\title{
UNHA EXPERIENCIA DE ADAPTACIÓN METODOLÓXICA Á DOCENCIA VIRTUAL E AS SÚAS IMPLICACIÓNS NO SEGUIMENTO POR PARTE DO ALUMNADO
}

\author{
Soneira Calvo, Carlos
}

Universidade da Coruña, Fac. de Ciencias da Educación, ORCID ID: 0000-0002-2902-268X

\section{RESUMO}

Neste traballo expóñense os cambios metodolóxicos, incluíndo os relativos á avaliación e ás titorías levados a cabo na materia Educación Matemática 1, de $1^{0}$ do grao en Educación Primaria para adaptar a docencia á modalidade virtual. Para as sesións asíncronas, graváronse vídeos explicativos sobre contidos teóricos aos que o alumnado podía acceder con antelación. As sesións síncronas dedicáronse principalmente a ilustrar a posta en práctica dos contidos teóricos expostos nos vídeos. Nelas os estudantes empregaron os recursos que ofrece Teams para se organizar en pequenos grupos dentro do grupo xeral, o que facilitou a interacción co docente. A avaliación foi continua, con varias probas síncronas individuais a través de Moodle e a realización dun traballo por grupos. As titorías realizáronse vía Teams e cobraron maior peso relativo respecto a cursos anteriores, con docencia presencial. 0 seguimento das distintas sesións foi, en termos xerais, sostido ao longo do cuadrimestre, e non houbo incidencias importantes na realización das probas on-line nin no funcionamento dos pequenos grupos. Porén, algúns fenómenos observados durante as sesións síncronas suxiren posíbeis anomalías no xeito de atender á sesión. Os resultados da avaliación foron máis positivos ca nas edicións presenciais da materia.

PALABRAS CLAVE: docencia virtual, metodoloxía docente, avaliación, titoría. 


\section{CITA RECOMENDADA:}

Soneira Calvo, Carlos (2021): Unha experiencia de adaptación metodolóxica á docencia virtual e as súas implicacións no seguimento por parte do alumnado. En García Naya, J.A. (ed.) (2021). Contextos universitarios transformadores: a nova normalidade académica. Leccións aprendidas e retos de futuro. V Xornadas de Innovación Docente. Cufie. Universidade da Coruña. A Coruña (pág. 379-389) DOI capítulo: https://doi.org/10.17979/spudc.9788497498180.379

DOI libro: https://doi.org/10.17979/spudc.9788497498180

\section{ABSTRACT}

This paper presents the methodological changes, including those related to the assessment and tutorials carried out in the subject Educación Matemática 1, corresponding to the $1^{\text {st }}$ course of the degree in Primary Education, in order to adapt teaching to the virtual modality. Regarding the asynchronous sessions, explanatory videos about theoretical contents were recorded and students could access to them in advance. The synchronous sessions were mainly devoted to illustrating the implementation of the theoretical contents. In these sessions, the students used the resources provided by Teams to work in small groups, which facilitated the interaction with the teacher. The evaluation was continuous, with individual synchronous tests through Moodle and a collaborative work. Tutorials were carried out via Teams and gained more relative weight compared to previous face-to-face teaching courses. The follow-up of the sessions was, overall, sustained throughout the semester, with no significant incidents in the conduct of the online tests nor in the operation of the small groups. However, some phenomena observed in the synchronous sessions suggests that episodes of lack of engagement could have happened. The results of the evaluation were more positive than in the face-to-face editions of the subject.

KEY WORDS: online teaching, teaching practises, assessment, tutorial 


\section{INTRODUCCIÓN}

A expansión do covid-19 dende comezos do 2020 e as medidas de hixiene sanitaria necesarias para paliar os seus efectos supuxeron un cambio importante en moitos ámbitos da vida cotiá. En particular, unha das medidas tomadas é o distanciamento social, que é de feito unha das máis eficaces para conter unha pandemia (Ahmed, Zviedrite \& Uzicanin, 2018). Isto afectou a moitas actividades da nosa sociedade, entre elas a docencia universitaria.

No sistema universitario español, a partir das recomendacións do Ministerio de Universidades (2020) acadouse un certo consenso entre as distintas institucións para se adaptar á nova situacións, plasmada nunha serie de orientacións para os docentes de cara á planificación da docencia de cara ao curso 2020-2021. Contémplanse tres modalidades de docencia en función da situación sanitaria: presencial, semipresencial ou híbrida, e online. Ademais, con carácter xeral recoméndase a docencia presencial e reivindícase a súa contribución á calidade da docencia universitaria (Area-Moreira, Bethencourt-Aguilar, Martín-Gómez \& San NicolásSantos, 2021). Isto mesmo despréndese das indicacións dadas aos docentes pola UDC (2020a, 2020b).

Destacamos tamén que á hora de valorar unha experiencia de docencia híbrida ou online cómpre distinguir entre a docencia online propiamente dita, e a chamada docencia remota de emerxencia (Bozkurt \& Sharma, 2020). En efecto, a primeira atende a diversos criterios, entre eles unha alta especialización do profesorado. Sen embargo, ante unha situación na que é necesario facer unha adaptación rápida ante unha situación de emerxencia, cumprir eses criterios resulta difícil (Niño, Castellanos-Ramírez, \& Patrón, 2021).

\section{DESCRICIÓN DA EXPERIENCIA}

A adaptación levouse a cabo na materia Educación Matemática 1 do $1^{0}$ curso do grao en Educación Primaria. É unha materia obrigatoria de 6 créditos impartida no $2^{\circ}$ cuadrimestre, que 0 curso 2020-21, no que se levou a cabo a experiencia contou con 145 matriculados. 
Por mor da redución do aforo das aulas debido á situación sanitaria, na facultade de Ciencias da Educación, que conta cun elevado número de matriculados no grao en Educación Primaria, en todas as materias de $1^{\circ}$ curso os estudantes repartíronse en 3 grandes grupos. Ademais, dentro de cada un destes grupos, formáronse outros 3 subgrupos, de entre 20 e 25 estudantes e foise máis restritivo á hora de autorizar cambios de grupo e sugbrupo. Procurábase con isto manter ao longo do curso grupos burbulla estábeis para limitar a expansión do virus en caso de contaxios. Nesta facultade optouse por un modelo de docencia híbrida, recomendándose que as sesións cos grupos grandes fosen virtuais asíncronas e as de cada subgrupo presenciais. Con isto respectábanse as indicacións dadas pola institución (UDC, 2020a, 2020b). A materia na que se realizou a experiencia foi en principio deseñada seguindo este modelo. Sen embargo, carencias de profesorado sobrevidas ao comezo do $2^{0}$ cuadrimestre e que afectaron tamén a outras materias, fixeron que para poder cubrir toda a docencia asignada respectando as medidas de hixiene sanitaria, todas as sesións da materia tiveran que se impartir virtualmente. Podería daquela dicirse que se tratou dunha docencia remota de emerxencia (Bozkurt \& Sharma, 2020).

As circunstancias que vimos de describir foron as que determinaron as modificacións que finalmente se levaron á práctica, resumidas na Figura 1. Para 0 seu deseño, seguíronse as liñas de actuación propostas polas diversas institucións (Ministerio de Universidades, 2020; UDC, 2020a, 2020b).

As pautas xerais seguidas no deseño da docencia foron, por unha banda, facilitar que 0 alumnado manteña unha dedicación sostida á materia e adquira 0 mesmo nivel de competencias ca na modalidade presencial. Estas pautas están moi ligadas pois na materia contemplamos a aprendizaxe non coma unha acumulación de contidos, senón que cada contido aprendido é a base necesaria para aprender 0 seguinte. Por outra banda, buscouse seleccionar aqueles recursos ofrecidos pola UDC que non implicasen medios tecnolóxicos custosos nos equipos ou no domicilio do alumnado para evitar que este se vise afectado pola fenda dixital. 


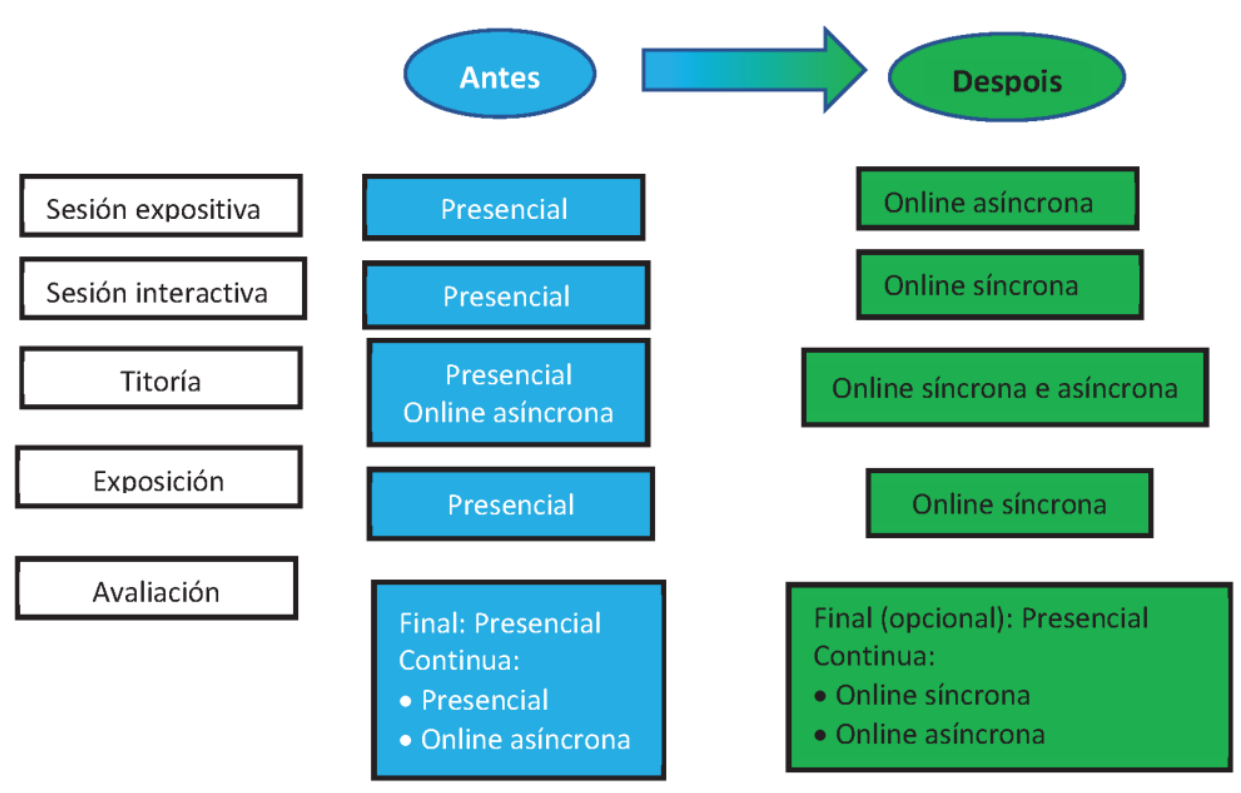

Figura 1. Esquema das modificacións

Como apoio á docencia subíronse ao Moodle documentos adicionais sobre como ía desenvolverse a materia. Uns expoñían a temporalización das distintas actividades a realizar cada semana, e outros coa descrición das tarefas obrigatorias e os seus criterios de avaliación. Isto fíxose no menor tempo posíbel, ante a previsión de que o alumnado necesitase dun período de adaptación aos trocos. En particular, aínda que os contidos non variasen, os trocos metodolóxicos podían afectar á planificación horaria do traballo autónomo feita por cada estudante. Á súa vez, isto podería provocar que parte do alumnado variase os seus horarios de asistencia ao centro. De feito, algunhas persoas visualizaban os vídeos e seguían as sesións síncronas dende a propia facultade, e outras dende 0 seu domicilio. Como consecuencia, algúns grupos de traballo reorganizaron levemente as tarefas grupais para maximizar o tempo no que todos coincidían na facultade.

En canto ás sesións de aula, en cursos anteriores as sesións cos grupos grandes consistían principalmente na exposición na aula dos contidos teóricos, e tiñan a vantaxe de que 0 alumnado podía formular dúbidas sobre os mesmos nese momento. Neste curso, estas 
sesións transformáronse na visualización de vídeos. Estes consistían en presentacións ofimáticas con voz gravada nas que o docente expoñía os contidos teóricos, con vídeos inseridos nos que se ve ao docente manipulando material estruturado. Para a súa realización, feita co paquete Office 365 por ser o ofrecido a nivel institucional, seguíronse as directrices dadas en Domínguez, Pampillón e Armas (2013) e en Peña (2019).

Para cada sesións expositiva, en vez dun único vídeo graváronse varios de menor duración, subíronse á plataforma Stream e incorporouse o enlace na páxina de Moodle da materia. En Stream os vídeos estaban vinculados ao equipo da materia na plataforma Teams. Usáronse, de forma integrada, exclusivamente ferramentas ofrecidos pola UDC a nivel institucional para docentes estudantes.

As sesión síncronas adoitaban dividirse en dúas partes. Na primeira 0 docente expoñía brevemente os contidos teóricos do vídeo que se ían usar na sesión, facendo fincapé naquelas ideas que consideraba máis difíciles, e atendíase unha primeira rolda de dúbidas sobre os mesmos. Na segunda, os estudantes organizábanse en grupos duns 5 membros en conversas internas en Teams para realizar distintas actividades de aplicación dos contidos teóricos. Cada certo tempo as chamadas grupais poñíanse en agarda, instábase aos grupos a que expuxesen a súa execución da actividade e facíase un comentario de todo o grupo ou unha corrección por parte do docente. De seguido, o docente presentaba a seguinte actividade. Ademais, en todo momento os estudantes podían retomar a chamada grupal para lle formular dúbidas ou expoñer observacións ao docente.

Realizáronse vía Teams titorías grupais e individuais. Unha das tarefas avaliábeis consistía na realización en pequenos grupos dun traballo tutelado, e nese contexto programouse unha titoría grupal de carácter obrigatorio. A data e franxa horaria foi concordada con cada grupo grande das sesións interactivas, para que todos puidesen asistir. Despois, o docente fixou un horario estimado para iniciar a sesión con cada pequeno grupo de estudantes, atendendo na medida do posíbel as preferencias dos estudantes. Este horario tivo algunhas variacións porque varios grupos precisaron máis tempo. Ademais, a algúns grupos comunicaron 
imprevistos de última hora que xustificaron a realización da súa sesión noutra data. Ao aproximarse a hora de inicio estimada para un pequeno grupo, os seus membros debían iniciar unha chamada grupal entre os seus membros, e en canto visen que 0 indicador de actividade do docente en Teams estaba en verde, convidalo á chamada. Isto pretendía axilizar 0 proceso.

Realizáronse ademais outras titorías ao longo do curso, tanto grupais como individuais, por petición dos estudantes, por Teams, correo e teléfono.

Os estudantes puideron escoller por dúas formas de avaliación. Unha continua, con probas síncronas online en Moodle e a entrega de tarefas tamén en Moodle. A outra opción era unha avaliación mediante unha proba obxectiva final, escrita e presencial. As datas e hora das probas síncronas estiveron dentro do horario oficial reservado polo centro para a materia. Fixáronse antes do comezo do curso, a información subiuse ao Moodle o día antes do comezo das aulas, e 0 procedemento explicouse na $1^{\text {a }}$ sesión con cada grupo. Ante as indicacións institucionais sobre a necesidade de evitar os efectos dunha posíbel fenda dixital entre estudantes, usáronse probas tipo test, pois poden facerse con ordenador mais tamén con móbil e non requiren gran velocidade de conexión. Ademais, en caso de fallar un tipo de conexión ou dispositivo podíase usar 0 outro. Durante a realización das mesmas os estudantes podían consultar co docente vía Teams en directo para consultar dúbidas.

\section{RESULTADOS}

En canto ao seguimento da materia por parte do alumnado, a actividade en Moodle ata abril recóllese na Figura 2. Se nos fixamos nos nodos correspondentes aos días de aulas síncronas, o seguimento foi sostido ao longo do curso. 0 descenso entre finais de marzo e comezos de abril correspóndese coas vacacións de Semana Santa. 


\section{Usuarios activos}

75

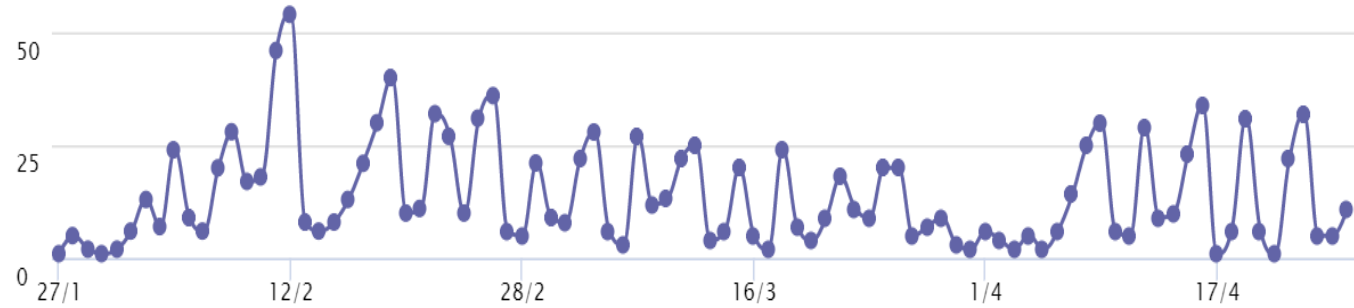

Figura 2. Actividade en Teams de febreiro a abril.

Sobre os vídeos expositivos, tras un elevado número de visualizacións do primeiro, despois estas estabilizáronse ao longo do curso (Figura 3).

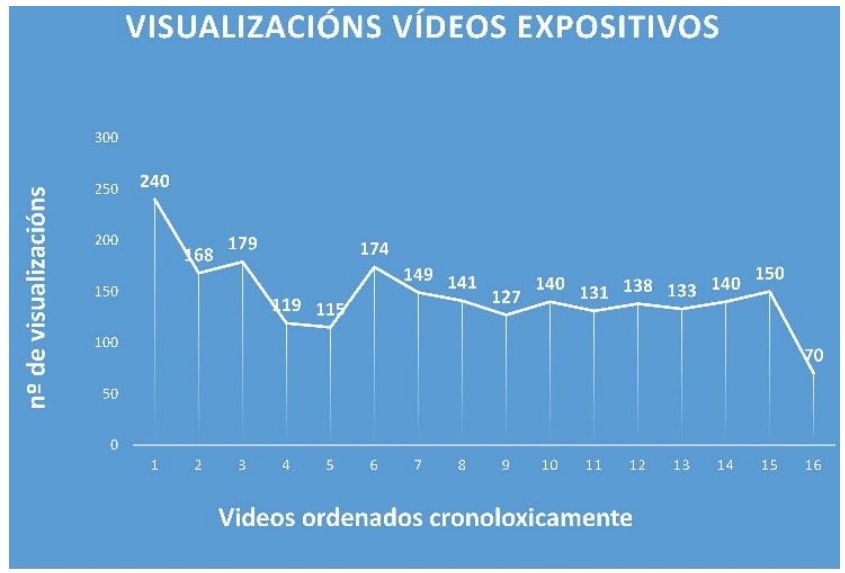

Figura 3. Visualizacións dos vídeos expositivos

No seguimento das sesións síncronas e asíncronas puido producirse un certo solapamento de recursos entre apuntamentos dixitalizados, vídeos asíncronos e sesión síncronas. En efecto, a $1^{\text {a }}$ parte das sesión síncronas dedicábase a repasar os puntos dos apuntamentos susceptíbeis dunha maior dificultade, e en moitas ocasións os estudantes manifestaron non ter visto os vídeos con antelación. Ademais, ao ser gravadas, os estudantes podían acceder a estas 
sesións en calquera momento posterior á sesión. Ante 0 posíbel solapamento, 0 docente preguntoulle ao alumnado se prefería obviar o repaso aos comezos das sesións, pero mantívose porque todos os grupos manifestaron que preferían continuar a facelo.

En canto á avaliación, a práctica totalidade do alumnado presentado optou pola modalidade de avaliación continua. Nas probas síncronas non se produciron maiores incidencias. Algúns estudantes tiveron caídas puntuais de conexión ou problemas cos dispositivos, mais puideron palialas no propio momento, en ocasións con indicacións do docente vía Teams, e continuar coa proba. Os resultados académicos foron mellores ca nas edicións presenciais da materia, cun maior índice de estudantes que superaron a materia na $1^{\mathrm{a}}$ oportunidade.

\section{CONCLUSIÓNS}

A partires do exposto na sección anterior, os resultados poden cualificarse de positivos se temos en conta que a experiencia se adscribe máis ben a unha situación de ensino remoto de emerxencia (Bozkurt \& Sharma, 2020) e o seguimento dos estudantes con esta modalidade tende a ser peor ca coa docencia en liña propiamente dita (Niño e outros, 2021).

Sen embargo, cómpre facer algunhas puntualizacións. Sobre 0 seguimento das sesións síncronas, os datos finos indican que moitos suxeitos se conectaban e desconectaban ao longo da sesión. Isto non é necesariamente un indicio de falta de seguimento, pois na gran maioría dos casos, a duración da desconexión era moi breve e pode ser atribuída a cortes na conexión. Sen embargo, para testar o seguimento, o docente formulaba ao longo da sesión preguntas ao grupo sobre as actividades en curso, e cando non había resposta, particularizaba a algún estudante concreto. 0 estudante escollíase ao chou, e así se facía saber ao grupo. Ocorreu nalgunhas ocasións que a persoa interpelada non contestaba nin amosaba estar a escoitar, aínda concedendo tempo máis ca dabondo para meditar a resposta e repetindo, en ton amábel, o nome. Unha interpretación plausíbel é que 0 aludido se conectara á sesión formalmente pero non a seguise de xeito efectivo. 
Actuar sobre este fenómeno presenta dúas dificultades. En efecto, dado o volume de estudantes en cada sesión, resulta difícil facer esta comprobación con todos os estudantes sen comprometer o traballo dos contidos planificado. Alén diso, tamén é difícil demostrar que en efecto 0 estudante non está a seguir a sesión, pois pese á solidez dos indicios, non pode descartarse totalmente un erro informático. Por outra banda, cabe ter en conta tamén que 0 déficit de atención prodúcese tamén nas sesións presenciais.

Ademais, 0 alumnado foi, en xeral, menos participativo ca nas edicións presenciais da materia. Ser consciente de que as sesións eran gravadas puido ser unha das causas.

Para finalizar, comparando a docencia presencial en cursos anteriores e a online do presente, consideramos preferíbel a presencial.

\section{REFERENCIAS}

Ahmed, F., Zviedrite, N., \& Uzicanin, A. (2018). Effectiveness of workplace social distancing measures in reducing influenza transmission: a systematic review. BMC Public Health, 18, 518. Recuperado de https://doi.org/10.1186/s12889-018-5446-1

Area-Moreira, M., Bethencourt-Aguilar, A., Martín-Gómez, S. \& San Nicolás-Santos, M. B. (2021) Revista de Educación a Distancia, 65(21). Recuperado de https://revistas.um.es/red/article/view/450461

Bozkurt, A. \& Sharma, R. (2020). Emergency remote teaching in a time of global crisis due to CoronaVirus pandemic. Asian Journal of Distance Education, 15(1), i-vi. Recuperado de http://www.asianjde.com/ojs/index.php/AsianJDE/article/view/576

Centro Universitario de Formación e Innovación Educativa (2020a). Como transformar a miña docencia presencial en docencia virtual. Algúns consellos básicos. Recuperado de https://sway.office.com/s/qLnFQjuOyuYVtkOi/embed

Centro Universitario de Formación e Innovación Educativa (2020b). Como diseñar una buena presentación educativa. Recuperado de https://www2.slideshare.net/CUFIE_UDC/comodisear-una-buena-presentacin-educativa 
Domínguez, E.; Pampillón, A.; de Armas, I. (2013). Rúbrica para evaluar la calidad de los Materiales Educativos Digitales. Madrid: Universidad Complutense de Madrid.

Ministerio de Universidades (2020). Recomendaciones del Ministerio de Universidades a la comunidad universitaria para adaptar el curso universitario 2020-2021 a una presencialidad adaptada y medidas de actuación de las universidades ante un caso sospechoso o uno positivo de covid-19. Recuperado de https://www.universidades.gob.es/stlls/universidades/ministerio/ficheros/COVID/Recomen daciones_del_Ministerio_de_Universidades_para_adaptar_curso.pdf

Niño Carrasco, S. A, Castellanos-Ramírez, J. C. \& Patrón Espinosa, F. (2021). Contraste de experiencias de estudiantes universitarios en dos escenarios educativos: enseñanza en línea vs. enseñanza remota de emergencia. Revista de Educación a Distancia, 65 (21). Recuperado de https://revistas.um.es/red/article/view/440731/298601

Peña Cabanas, A. M. (2020). Deseño e implementación de materiais didácticos multimedia para a docencia. A Coruña: CUFIE.

Universidade da Coruña (2020a). Orientacións para a programación da actividade docente: curso 2020-2021.

Recuperado de https://www.udc.es/export/sites/udc/covid19/_galeria_down/orientacions.pdf_206306929 9.pdf

Universidade da Coruña (2020b). Nota aclaratoria sobre a instrución da vicerreitoría de planificación académica innovación docente sobre a gravación das aulas e demais actividades docentes non presenciais. Recuperado de https://sede.udc.gal/services/electronic_board/EXP2020/009443/document?logicalld=db b3c125-356c-4009-b2d83bb2243c4838\&documentCsv=MTHENJ1LI242CDEDB84RKD1G 
